\title{
JOSÉ CORREDOR-MATHEOS, Corredor de fondo. Memorias, Barcelona, Tusquets, 2016, 541 pp.
}

$M^{a}$ ELENA RODRÍGUEZ VENTURA

\section{IES Marina Cebrián, San Cristóbal de La Laguna}

José Corredor-Matheos (Alcázar de San Juan, 1929), reconocido poeta de la denominada generación del cincuenta, ha publicado recientemente sus memorias en la editorial Tusquets en Barcelona, ciudad en la que reside desde 1942. Este libro, titulado Corredor de fondo, testimonia no solo sus vivencias personales sino también las relaciones más significativas que mantuvo con un sinfín de personalidades relevantes del mundo de la cultura de nuestro país. Su trayectoria es más que fecunda, no solo en el ámbito poético, en el que ha sido galardonado con el Premio Boscán de Poesía en 1961 y con el Premio Nacional de Poesía en 2005, sino también en otras ramas de la cultura como es la crítica de arte o la traducción (Premio de Artes Plásticas de la Generalitat de Cataluña en 1993 y Premio de Traducción entre Lenguas Españolas en 1984). Su legado y aportación a toda una vida dedicada al arte y la literatura son reconocidas a su vez con la Creu de Sant Jordi en 1989 y la Medalla de Oro al Mérito Cultural por el Ayuntamiento de Barcelona en 2004. Ha realizado estudios sobre arte contemporáneo, cerámica popular, arquitectura y diseño industrial; ha trabajado como editor en Éxito, Espasa Calpe y Edicions 62; es académico de la Real Academia de Bellas Artes de San Fernando y de la Reial Acadèmia de Belles Arts de Sant Jordi, asesor artístico del Colegio de Arquitectos de Barcelona, miembro de la Academia Internacional de cerámica, fundador y primer presidente de la Agrupación de Actividades Artesanas y asesor artístico de la fundación Caixa de Cataluña.

Con todo, este libro se nos presenta como un compendio de lo que ha sido nuestra historia más reciente y todos sus avatares socio-políticos y culturales, así como el papel de sus activistas más destacados. El autor, con un tono sereno y afectuoso nos habla siempre desde la comprensión amable y el no enjuiciamiento, rasgos propios de quien, a partir de una ingente experiencia, ha alcanzado un alto grado de conocimiento vital.

En su comienzo, asistimos a la vida de pueblo en Alcázar de San Juan durante la Segunda República, a través de los 
recuerdos de una infancia que constituye para el poeta «un mito, de sagrado significado» (p.19). La presencia del campo y su anchura alimentan ya su temple para con la naturaleza y su sincero amor por la tierra manchega.

Perteneciente a la generación de los llamados "niños de la guerra», esta le sorprende una vez se ha trasladado con su familia a Vilanova i la Geltrú, localidad de la costa catalana que también dejará honda huella en el autor. Allí los bombardeos, los refugios subterráneos, el hambre y una muestra más de un país súbitamente dividido, tal y como sucedería con sus tíos paternos, adheridos a bandos contrarios. Nuevamente trasladados, esta vez a Barcelona, los primeros y duros años de la posguerra se llevarían de forma accidental al padre del autor, lo que dificultará, pero no impedirá, sus estudios de Derecho. Es la década de los cuarenta, y el poeta testimonia la mediocridad de una educación sujeta a las imposiciones del nuevo régimen. No obstante, es época también de buenos amigos con los que compartir lecturas clandestinas, el cine de intriga, la música de jazz...

Durante los años cincuenta y sesenta Corredor-Matheos desempeñará su trabajo como editor, sobre todo, en Espasa-Calpe. En este momento se introducirá en el ambiente literario y también teatral de la época. Asiste a tertulias y reuniones celebradas en El Turia (con Ana María Matute, Lorenzo Gomis o Juan Goytisolo, entre otros), el Haz de Noveles en el salón de té Vienés, o las reuniones del Términus, ya desaparecido. Mantendrá contacto y amistad con Alfonso Costafreda, Enrique Badosa, Miquel Martí i Pol y, de manera especial, con Jesús Lizano, quien da pie a pintorescas anécdotas compartidas con el propio autor. En el Congreso Internacional de Poesía de Salamanca de 1953, conocería a muchos otros poetas catalanes: Carles Riba, Clementina Arderiu, J. V. Foix, Marià Manent, Tomás Garcés, Ricard Permanyer, Joan Teixidor y Joan Perucho. Asimismo, en este Congreso entablará relación con uno de sus grandes amigos, el poeta manchego Ángel Crespo, al que considera que actuó como hombre-puente entre Madrid y Barcelona al fomentar colaboraciones en revistas, algunas de ellas censuradas. Mención aparte merece, de entre los autores catalanes, el poeta Salvador Espriu, de cuyo libro, Cementiri de Sinera, Corredor-Matheos realizó una traducción para una edición bilingüe en 1969. Con Espriu, el autor hablaría sobre sus preferencias poéticas, sobre la espiritualidad de otras culturas y religiones, o sobre astrología. A través del poeta Ramón de Garciasol, Corredor-Matheos se introduce también en la famosa tertulia madrileña del Café Gijón, presidida por el poeta del 27 Gerardo Diego. Allí conocería a José García Nieto, Leopoldo de Luis, Francisco Umbral, Luis López Anglada, Manuel Álvarez Ortega o Félix Grande, entre otros. A su vez, en este Café coincidirá con el dramaturgo Antonio Buero Vallejo, con quien compartirá interesantes conversaciones durante varios paseos nocturnos. Además de 
Gerardo Diego, el poeta nos habla de su relación con otros autores del 27: Vicente Aleixandre, padrino de las nuevas generaciones de poetas, Dámaso Alonso, que colaborará con sus estudios en los Suplementos de la Enciclopedia Espasa, y el exiliado Rafael Alberti, con quién mantendrá una estrecha amistad toda su vida. Corredor-Matheos organizó en 1970 el primer homenaje importante a Alberti celebrado en España después de la guerra civil, que contaría con la colaboración de personalidades como Robert Marrast, José María de Cossío, Gregorio Prieto y antiguos amigos del poeta. La exposición no estaría exenta de dificultades con la Jefatura Superior de Policía, la censura o altercados anónimos. Los encuentros con el poeta gaditano han propiciado que en estas memorias se describa el ambiente que se respiraba en su casa de Roma, sus inquietudes políticas dentro del Partido Comunista, sus relaciones con poetas y pintores, su vida familiar y sus controversias amorosas.

Durante las siguientes décadas, cabe destacar su incursión en la Asociación Colegial de Escritores de España (ACE) y las amistades que inició o retomó con poetas como Ángel Crespo y su esposa Pilar Gómez Bedate, Enrique Badosa, José Luis Jiménez-Frontín o el pintor Josep Guinovart, con quienes se reunía de forma periódica en lo que denominaban «Peña de los Primeros Viernes de Mes» (p. 497). Esporádicamente aparecían en estas tertulias otras personalidades relevantes como Carlos Edmundo de Ory, Salvador Pániker o Carlos Castillo del Pino. En los noventa, coincidirá con el poeta chileno Gonzalo Rojas, de quien nos dice, con gran estima, que es «el escritor famoso más sencillo y modesto que he conocido» (p. 499). Ya entrado el nuevo milenio y con motivo del Premio Nacional de Poesía en 2015 por su obra El don de la ignorancia, Corredor-Matheos advierte que comienza un nuevo período en su relación con los ambientes literarios. Se propician interesantes viajes sobre todo a países de Extremo-Oriente, pero también a otras ciudades españolas donde se celebrarán eventos relacionados con el mundo de la poesía. Allí se irá topando con compañeros de vocación y promoción tales como Antonio Gamoneda o Francisco Brines. Otros autores más jóvenes con los que ha entablado amistad han sido Jaime Siles, Abelardo Linares, Carlos Marzal, Vicente Gallego, Chantal Maillard..., entre muchos otros.

Como crítico de arte (a partir de 1961), llegará a convertirse en fundador y primer presidente de la Asociación Catalana de Críticos de Arte, por lo que ejerció como comisario del arte catalán en la Expo de Sevilla (1992), y realizará innumerables exposiciones y estudios de autores a los que también conoció muy de cerca. Al principio se relacionó sobre todo con los pintores y amigos Josep Guinovart y Julián Grau Santos, así como con los poetas y críticos Juan Eduardo Cirlot y Joan Perucho. Al entrar en los círculos más innovadores del momento se manifestó por ejemplo como defensor de la creación del Museo de Arte Contemporáneo, en Barcelona, idea abalada por el 
también escritor y crítico de arte Alexandre Cirili i Pellicer. Recuerda el autor los barceloneses Salones de Octubre y su apuesta por el arte más vanguardista: el grupo Dau al Set, con Joan Ponç y Antoni Tápies, entre otros, y su referente, sucesor del surrealismo, Joan Miró.

El poeta considera que "todo verdadero artista es, de un modo u otro, personalmente muy curioso» (pp. 227228) y da cuenta de ello al describir a autores como Joan Miró, Salvador Dalí o a Antoni Tàpies. Encontramos en su libro dos capítulos específicos en los que aborda su relación con Miró y con Dalí. De Joan Miró comenta que era hombre de buen carácter y generoso, lo que ocasionó varios abusos o gestos oportunistas por parte de quienes se acercaban a él. El poeta ha publicado tres libros y numerosos artículos sobre su obra, y ha participado en la exposición titulada Miró Otro de 1970 efectuada en la sede del Colegio de Arquitectos de Barcelona. Con Salvador Dalí mantuvo una relación más profesional que amistosa aunque con numerosos encuentros, y CorredorMatheos lo recuerda como un «ser extraordinario» (p. 270) al que se le debían perdonar sus provocaciones, por tratarse precisamente de eso, de provocaciones, que recordaban la mayoría de las veces a las manifestaciones dadaístas de los años 20. El poeta y crítico dirigió la edición en Blume del libro Dali de Draeger de 1968 y organizó una insólita presentación del mismo, protagonizada por el propio Dalí. De ambos artistas, el poeta admira la inocencia infantil que mantuvieron en su edad adulta y también «el carácter de seres perdidos en la sociedad» (p. 239). Con Antoni Tàpies, sin embargo, hubo siempre una conveniente distancia, ya que según nos cuenta este dio muestras de una actitud poco íntegra con los artistas considerados rivales. No obstante, su obra también ha sido su objeto de estudio, en el libro Antoni Tàpies. Materia, signo, espíritu (1992). De esta época es también la anécdota vivida con otro autor de Dau al set, el poeta Joan Brossa, quien organizó un evento bastante original en 1979, que consistía en realizar una excursión nocturna por la ciudad de Barcelona con un itinerario lleno de sorpresas.

Corredor-Matheos también se ha interesado en diferentes momentos por el pintor y orfebre Jaume Mercadé, los paisajes de Pere Gastó, el pintor naïf Joan Brotat, o Albert Ràfols-Casamada y su «abstracción serena» (p. 244), el pintor, grabador y escultor exiliado Antoni Clavé, los también escultores Joan Rebull, Apel·l es Fenosa o Josep Maria Subirachs $\mathrm{y}$, dentro del mundo de la fotografía, autores como Català Roca o Tony Vidal.

En Madrid entra en contacto con el grupo El Paso, creado en 1957, y conocerá a los pintores de vanguardia Rafael Canogar, Manolo Millares, Manuel Rivera, Antonio Suárez, Antonio Saura, Manuel Viola, y los escultores Pablo Serrano y Martín Chirino. También se interesará por pintores de otras tendencias como Eusebio Sempere, José Hernández, Álvaro Delgado o incluso Benjamín Palencia. Naturalmente aparecen en estas memorias otros muchos nombres con los

LECTURA Y SIGNO, 11 (2016), pp. 101-106 
que igualmente el poeta ha compartido el interés por el arte y su repercusión en la realidad. De algunos de ellos nos dibuja su perfil humano y las relaciones, no siempre cordiales, que mantuvieron entre sí por ser partidarios de concepciones artísticas diferentes.

En otro capítulo de sus memorias recuerda también los importantes lazos mantenidos con las islas Canarias, a propósito del estudio de autores como Pepe Dámaso, el ya nombrado Manolo Millares y Juan Ismael. Con éste último mantuvo una estrecha relación. Lo conoció en 1956 a través de la poeta grancanaria Pino Ojeda, que era amiga de ambos. Sin embargo, la época de mayor contacto con el artista canario se dio en los años cercanos a 1970, cuando Corredor-Matheos organizó en Barcelona la exposición del grupo ADLAN (Amics de l'Art Nou), uno de cuyos núcleos se encontraba en Tenerife. A su vez, al frente de las vanguardias en Canarias se hallaba el crítico de arte Eduardo Westerdahl, con quien Corredor-Matheos colaboró en varias ocasiones y mantuvo una fructífera correspondencia y apreciada amistad.

Algunos años más tarde, siguiendo con su labor de crítico, cruzaría las fronteras de nuestro país y visitaría países como Cuba, donde se interesó por la obra del pintor surrealista Wilfredo Lam o de René Portocarrero. En México prepararía una monografía sobre Rufino Tamayo, con su singularidad indígena, de quien el poeta ha dicho que desarrollaba un arte "profundo y libre» (p. 447). En Italia había asistido a la Bienal de Vene- cia de 1968 y diez años después participaría en el congreso internacional Crítica 0 . Otro de los lugares que señala en estas memorias es Japón, donde presentó una exposición en 1992 sobre el pintor japonés residente en Barcelona, Shichiro Enjoji.

En los años que van de 1954 a 1960, antes de iniciarse en la crítica de arte, Corredor-Matheos mantuvo una estrecha relación con el mundo del teatro. Formaba parte de un grupo que se llamaba «Palestra de Arte Dramático», que derivó en el teatro Candilejas de Barcelona, ahora desaparecido. Allí ejerció como actor, como ayudante de dirección y como director. Durante aquellos años, el poeta recuerda la representación de obras de Azorín o Molière, y el trabajo del director Diego Asensio y de amigos actores y actrices como Amparo Baró, Julieta Serrano o Alicia Hermida, entre otros. Además, escribió una pieza en un acto titulada, Una partida de cartas, estrenada en 1960 por el grupo de teatro de la facultad de Derecho de la Universidad de Barcelona.

En el título de estas Memorias, Corredor-Matheos combina su propio apellido con otra de sus innumerables dedicaciones: el atletismo, deporte que practicó desde 1947 hasta 1956 en el equipo del Club Natación Barcelona. Un título acertado si tenemos en cuenta su arrolladora andadura y, al mismo tiempo, una alusión inconsciente a su modo de habitar la realidad, siempre desde su fondo y hondura. 
En este libro, el autor se centra más en sus compañeros de viaje que en sí mismo, y los observa como quien ve una película, mientras se cuela por los intersticios de la acción, para retener y subrayar, de entre toda la vorágine, lo que solo los grandes poetas detectan: lo puramente esencial. Si atendemos a su poesía, diferente a la de sus compañeros de promoción, y considerada como excepcional dentro de una línea espiritual orientalista, comprenderemos la ausencia en sus memorias de un yo latente, de un protagonista absoluto de estos recuerdos, como sería lo esperable. En su trayectoria poética y también personal, se va decantando cada vez con mayor implicación por lo que la poesía china o japonesa y otros textos de sabiduría tradicional le han revelado. Las enseñanzas del Taoísmo, del Budismo zen, de la mística cristiana..., hacen que el autor asuma como actitud vital sus más significativos preceptos: la importancia de la percepción intuitiva y espontánea de la realidad, la anulación del ego para conectar con los demás seres, la dualidad o teoría de los opuestos $\mathrm{y}$, de manera primordial, la vacuidad, ese eje que vertebra y da respuesta a toda la existencia a partir de su disolución. Sin jamás retirarse de lo cotidiano y en contacto directo con lo inmediato, sus poemas se forjan siempre desde el presente, y este es un rasgo que también se ha extrapolado a sus memorias. La sensación que predomina en la lectura es la de estar sujetos a los instantes que el poeta narra, los cuales se reavivan en cada capítulo como en una primera evocación. Conviene incluir aquí algún poema de su último libro publicado, (Sin ruido, Barcelona, Tusquets, 2013, p. 125) para acercarnos un poco más a la figura del autor: «Arrancar / unos versos / al silencio / y sentir el vacío / donde todo / era árbol, / agua, / pájaro. / Plenitud, / la de ser / en el filo del viento.»

En estas Memorias, Corredor de fondo, asistimos a la vida de un hombre sabio, un "vir bonus et aequum», como le decía su padre, o un espectador «moderadamente apocalíptico» (p. 521), como él se denomina cuando analiza la sociedad actual. Hombre y poeta, CorredorMatheos ha sido partícipe de muchos tiempos, pero también, del no tiempo, esto es, de la trascendencia, originada tras una búsqueda interior que le ha llevado más allá de sí mismo y más allá de todo, donde el vacío resulta esclarecedor; donde no quedan más que «aromas, sonidos y aires musicales, de los que, tirando del hilo, puede salir todo» (p. 65). 